\title{
On accounting for problems demonstrated by children with SLI in the interpretation and production of passive construction*
}

Frenette Southwood and Johan Oosthuizen

Department of General Linguistics, Stellenbosch University, 7600, Stellenbosch, South Africa E-mail: fs@sun.ac.za and jo@sun.ac.za

\section{Introduction}

Specific language impairment (SLI) is a significant impairment in the spoken language ability of children in the absence of identifiable casual factors or obvious accompanying factors such as neurological deficits, mental challenges, hearing disabilities and emotional or behavioral problems (Leonard 1998: vi; Stark and Tallal 1981). According to Van der Lely (1996) ${ }^{1}$ and Rice, Wexler and Francois (2001), when compared to typically developing children who obtain similar language test scores, English-speaking children with SLI show greater difficulty in interpreting "full" passives, such as The teddy is mended by the girl. Children with SLI are also more likely to interpret "short" passives, such as The teddy is washed, as an adjectival construction - which can be paraphrased as The washed teddy - rather than as an agentless passive, i.e., a passive construction without the prepositional (by) agent phrase. Passive constructions are also problematic for children with SLI who speak a language other than English (cf. section 2), including those who speak Afrikaans (cf. section 3).

Although SLI is not a new field of study, the development of theoretical accounts of SLI is a relatively new focus in this field. This paper examines one linguistic account, namely the Computational Complexity Hypothesis ${ }^{2}$ of Van der Lely $(1994 ; 1996 ; 2003 ; 2005)$. The content of this account is presented in section 5 below. According to Van der Lely (1996: 
267; 2003: 127), her account offers an explanation for the problems that children with SLI demonstrate with passive constructions. In section 6 , we argue that this account in fact fails to offer an adequate explanation for these problems. In section 7, we consider three possible alternative explanations for these problems, each from the perspective of Minimalist Syntax. As background, some general assumptions and devices of Minimalist Syntax are set out in section 4 , followed by a brief discussion of two interrelated minimalist theories, namely those involving feature checking and movement. The exposition in section 4 is given for two reasons, namely (i) because Van der Lely's accounts which culminated in the Computational Complexity Hypothesis incorporate the concept movement and (ii) because Van der Lely (2003: 126) explicitly states that she works within, but is not "tied to", Chomsky's (1995a) Minimalist Program in her analysis of the language problems of children with SLI.

\section{Problems with passive constructions demonstrated by children with SLI who speak a language other than English}

Children with SLI who are speakers of languages other than English have also been reported to demonstrate problems with passive constructions. For example, Dalalakis (1994: 224) found that Greek-speaking children with SLI have difficulty understanding the passive. Fuduka and Fuduka (1994: 162, 164) reported that Japanese-speaking children with SLI fare significantly worse than age-matched controls in the interpretation of passive constructions, as well as in grammaticality judgements involving illicit passive constructions. Crago and Allen (1994) conducted a single case study in which the language of a 64-month-old Inuktitutspeaking child with SLI was compared to that of two children, namely (i) a typically developing peer, and (ii) a typically developing 25-month-old who performed at the same language level as the child with SLI. They found that a low percentage of verb-internal affixes marking passive was characteristic of the language of the child with SLI. What is also significant is that this child did not use any passive constructions in the 200 utterances examined; this is highly unusual in light of Allen and Crago's (1993: 115) finding that typically developing 2- and 3-year-old Inuktitut-speakers use passive constructions frequently. ${ }^{3}$ Babyonyshev, Hart and Grigorenko (2005) found that Russian-speaking children with SLI did not perform as well as typically developing Russian-speaking children in the interpretation of reversible passive constructions. ${ }^{4}$ Interestingly, the children with SLI performed best with so-called actional passives (such as A rooster was plucked by a goose), 
less well with psychological passives (such as A fox was consoled by a cow), and worst with perception passives (such as A giraffe was smelled by a monkey); no such differences across types of passives were observed for the typically developing children.

\section{Problems with passive constructions demonstrated by Afrikaans-speaking children with SLI}

Our preliminary data - collected from Afrikaans-speaking 6-year-olds with SLI, and from typically developing Afrikaans-speaking 3-, 4-, and 6-year-olds, as part of a larger study on SLI in Afrikaans (cf. Southwood 2007) - indicate that, in terms of their interpretation of passive constructions, Afrikaans-speaking children with SLI perform worse than typically developing age-matched controls, but on par with younger typically developing ones. Table 1 contains a summary of the results of a picture selection task consisting of 10 items. The children were requested to select the picture which matched the researcher's utterance, such as Die wurm word deur die voël gesien "The worm is seen by the bird". For each item, there was a target (in this case, a picture of a bird looking at a worm); a reversed distracter (a worm looking at a bird) and another, less related distracter (e.g., a picture of a bird looking at another bird). Four groups of children participated: typically developing 3-, 4- and 6-yearolds, and 6-year-old children with SLI. As shown in table 1, (i) all groups performed poorly, but the oldest unimpaired children outperformed the rest; (ii) there was great variability in all four groups; and (iii) for all groups, the error made most frequently was the selection of the reversed distracter.

Table 1. Results of picture selection task to assess interpretation of passive constructions

\begin{tabular}{|l|r|r|r|r|r|r|r|}
\hline \multicolumn{1}{|c|}{ Group } & \multicolumn{1}{|c|}{$\mathbf{M}$} & $\begin{array}{c}\text { Mean } \\
\text { /10 }\end{array}$ & $\begin{array}{c}\text { Mean \% } \\
\text { correct }\end{array}$ & $\begin{array}{c}\text { Minimum } \\
\text { score /10 }\end{array}$ & $\begin{array}{c}\text { Maximum } \\
\text { score /10 }\end{array}$ & $\begin{array}{c}\text { "Reversed" } \\
\text { errors }\end{array}$ & $\begin{array}{c}\text { Other } \\
\text { errors }\end{array}$ \\
\hline SLI (6 yrs) & 15 & 4.33 & $43 \%$ & 2 & 9 & $95 \%$ & $5 \%$ \\
\hline 3-year-olds & 6 & 4.50 & $45 \%$ & 2 & 7 & $97 \%$ & $3 \%$ \\
\hline 4-year-olds & 4 & 3.75 & $38 \%$ & 2 & 7 & $96 \%$ & $4 \%$ \\
\hline 6-year-olds & 15 & 5.53 & $55 \%$ & 0 & 10 & $96 \%$ & $4 \%$ \\
\hline
\end{tabular}

Regarding production of passive forms, a sentence completion task consisting of 10 items was conducted. Each child was shown a picture - for example, one of a boy chasing a horse - and was told Kyk iemand jaag vir iemand. Die perd ... "Look, someone is chasing someone. The horse ...". The children were then expected to complete the sentence based on the content of 
the picture. If they did not produce a passive construction, the item was repeated, but the word word "is" was then also provided by the researcher: Kyk iemand jaag vir iemand. Die perd word.... The results of the sentence completion task are presented in table 2. Again, the typically developing 6-year-olds outperformed the other three groups: They produced the greatest number of full passives as well as the greatest number of full and short passives combined. However, a large proportion of their attempts was ungrammatical - only the 4year-olds produced a greater number of ungrammatical plural forms than did the typically developing 6-year-olds. The 3-year-olds had a strong preference for the active form; this preference was also observed for the SLI group, but to a lesser extent.

Table 2. Results of sentence completion task to assess production of passive constructions

\begin{tabular}{|c|c|c|c|c|c|c|c|c|}
\hline \multirow[t]{2}{*}{ Group } & \multirow[t]{2}{*}{$\mathbf{N}$} & \multirow{2}{*}{$\begin{array}{l}\text { Gramma- } \\
\text { tical full } \\
\text { passive }\end{array}$} & \multirow{2}{*}{$\begin{array}{l}\text { Gramma- } \\
\text { tical short } \\
\text { passive }\end{array}$} & \multirow{2}{*}{$\begin{array}{l}\text { Ungramma- } \\
\text { tical passive } \\
\text { form }\end{array}$} & \multicolumn{2}{|c|}{ Active form } & \multirow[t]{2}{*}{ Other } & \multirow{2}{*}{$\begin{array}{l}\text { No re- } \\
\text { sponse }\end{array}$} \\
\hline & & & & & $\begin{array}{l}\text { Cor- } \\
\text { rect }\end{array}$ & $\begin{array}{c}\text { Re- } \\
\text { versed }\end{array}$ & & \\
\hline SLI & 15 & $10 \%$ & $9 \%$ & $11 \%$ & 31 & $11 \%$ & 22 & $6 \%$ \\
\hline 3-yea & 6 & $0 \%$ & $2 \%$ & $3 \%$ & $71 \%$ & $10 \%$ & $12 \%$ & $2 \%$ \\
\hline 4-year-olds & 4 & $\% \%$ & $20 \%$ & $30 \%$ & $17.5 \%$ & $5 \%$ & $17.5 \%$ & $0 \%$ \\
\hline 6-year-olds & 15 & $43 \%$ & $8 \%$ & $20 \%$ & $19 \%$ & $4 \%$ & $6 \%$ & $0 \%$ \\
\hline
\end{tabular}

The question arises as to how to account for the problems with passives demonstrated by children (of various languages) with SLI, taking into consideration recent developments in syntactic theory. Before turning to such accounts, some background on relevant aspects of Minimalist Syntax, the most recent theory of grammar within the generative framework, is provided.

\section{Aspects of Minimalist Syntax}

To begin, it is important to note that there is a distinction between the Minimalist Program (or Minimalism, for short) and Minimalist Syntax. The Minimalist Program is not a theory, but a research program for linguistic enquiry. ${ }^{5}$ Although there is no unique Minimalist approach to a specific linguistic phenomenon, research carried out from a Minimalist perspective has led to the development of a number of theories to account for various syntactic phenomena (Hornstein, Nunes and Grohman 2005: 6). These theories can collectively be referred to as "Minimalist Syntax". The version of Minimalist Syntax set out below is the one generally associated with Chomsky (1995a); where necessary, reference is made to more recent developments. 
Within Miminalist Syntax, the language faculty consists of two components, namely a lexicon and a computational system for human language $\left(\mathrm{C}_{\mathrm{HL}}\right)$ (Chomsky 1995a: 168). The lexicon specifies the lexical items with their idiosyncratic features. $\mathrm{C}_{\mathrm{HL}}$ derives a linguistic expression on the basis of a selection of lexical items. Such a selection is called a "Numeration" (Chomsky 1995a: 169). The derivation proceeds as the operation Merge strings the lexical items together in a binary fashion, and the operation Move $^{6}$ carries out the movement of syntactic objects in the expression.

At some point in the computation - known as the point of "Spell-Out" transferred to two distinct components, namely the phonological component and the semantic component. The mechanisms of the phonological and the semantic components construct two distinct types of representation, namely a phonetic form (PF) and a logical form (LF), respectively. PF serves as input to the sensorimotor system, whereas LF serves as input to the conceptual-intentional system. These two interface systems, both independent of the $\mathrm{C}_{\mathrm{HL}}$, are responsible for the actual sound form and semantic interpretation of linguistic expressions.

A derivation is said to "converge" if it produces a legitimate linguistic expression and to "crash" if it does not (Chomsky 1995a: 171). A derivation can converge or crash at either PF or LF, but must converge at both levels of interpretation - where "level of representation" refers to either LF or PF (Zwart 1993: 13) - if is to converge at all (Chomsky 1995a: 171). The legitimacy of a linguistic expression is determined by the principle of Full Interpretation, which specifies that uninterpretable grammatical features must be "checked" in order to be usable in the phonological and semantic components. ${ }^{8}$ In fact, the grammar is assumed to be "feature-driven", in the sense that movement of elements occurs so that feature checking can take place. As stated by Hornstein et al. (2005: 286, 293), feature checking is "triggered by the need to eliminate uninterpretable features from the computation".

Lexical items are defined as bundles of features, specifically phonological, semantic and grammatical features. Selecting a lexical item from the lexicon to form a part of a Numeration thus implies retrieving a set of features. Phonological features are interpretable at PF, but not at LF, whereas semantic features are interpretable at LF, but not at PF (cf. Chomsky 1995b: 
394). At the point of Spell-Out, the phonological features are sent to PF and the semantic ones to LF.

The question arises as to why lexical items possess uninterpretable features at all, as this seems contrary to the Minimalist assumption that economy (of elements and computations) is an optimal property of the language faculty (Chomsky 1993: 4; 1995a: 1). In the absence of a clear answer to this question, Hornstein et al. (2005: 293) suggest that movement is the mechanism used to eliminate uninterpretable features, the existence of which remains unexplained at present.

In Minimalist Syntax, construction-specific movement rules (e.g., passive, question formation, extraposition, etc.) and category-specific movement rules (e.g., NP movement, wh movement, V-to-I movement, etc.) of earlier theories of generative grammar have all been replaced by Move. ${ }^{9}$ Move essentially means "move nothing nowhere, unless as a last resort to prevent the derivation from crashing" (cf. Chomsky 1995a: 257 in this regard). This entails that a lexical item may only move for the purposes of feature checking, i.e., to eliminate uninterpretable features. For example, in an active construction, the object DP's semantically uninterpretable case feature is checked against that of the lexical verb (or the light verb $v$ in an expanded verbal projection); the case in question manifests as accusative. In a passive construction, by contrast, the relevant verbal element (the passive $\mathrm{V}$ or the light verb $v$ ) lacks a case feature against which that of the object DP can be checked. Hence, to avoid crashing at LF, the object DP has to move to the surface subject position so that its case feature can be checked against that of T. The outcome of this movement is that the object DP ends up with nominative case in passive sentences.

The above exposition of aspects of Minimalist Syntax forms the background against which the content and merit of the Computational Complexity Hypothesis is discussed below.

\section{The Computational Complexity Hypothesis}

According to Van der Lely's (1994) account, the language deficits of children with SLI stem from a selective impairment in establishing the structural relationship between dependent 
constituents. This impairment has the effect that certain obligatory movement operations in the grammar of non-impaired speakers are optional in the grammar of children with SLI.

Van der Lely (2003: 127) claims that the relevant linguistic deficits in children with SLI should not be ascribed to the total absence of Move, but rather to the optionality of this operation in the grammar of such children. She considers two principles involved in movement. The first, which is obeyed by children with SLI, is that constituents only move if (i) they have features that need to be checked, or (ii) they have features against which those of some other constituent must be checked. Thus, a verb with the feature [+past] will only move to the TP if the T has a tense feature that must be checked, and not for any other reason. On the Computational Complexity Hypothesis, children with SLI demonstrate problems in establishing dependent relationships between different constituents, and thus in establishing the syntactic domain in which the feature can be checked. Therefore, in the grammar of these children, a constituent does not always move to the correct syntactic domain for checking purposes. Van der Lely (1996: 246) claims that the past tense feature of a verb can, in the grammar of children with SLI, be checked against either the finite TP or another constituent which is marked for "time" (such as an adverb of time). For this reason, it often seems as if the phonetic realisation of such features is optional in the language of children with SLI. Moreover, Van der Lely (1996: 246) argues that this optionality leads to the omission of grammatical morphemes from obligatory contexts, and not to their insertion in inappropriate contexts. According to her (1996: 246), this means that a checked tense feature will be realised phonologically in the correct form; however, an unchecked feature will be absent from the phonological form of the utterance and therefore the verb will appear in its infinitival form.

The second principle involved in movement, according to Van der Lely (2003: 127), is that Move is forced if a constituent's features have not yet been checked. She claims that this principle is "missing" in the grammar of children with SLI. This absence results in Move being an optional operation in the grammar of these children; accordingly, some features are left unchecked. 


\section{Merit of the Computational Complexity Hypothesis}

As mentioned above, Van der Lely (2003:126) states that she works within Chomsky's (1995a) Minimalist Program in her analysis of the language problems of children with SLI, although her account is not "tied to" this programme. Perhaps, then, one could view the ongoing revision of her account, first proposed in 1994, as an attempt to keep abreast with developments in Minimalist Syntax. However, Van der Lely seems to adopt a rather eclectic approach when deciding which principles of Minimalist Syntax to incorporate into her account. For example, she provides the following explanation for the problems that children with SLI demonstrate with the interpretation of (certain types of) passive constructions: "The SLI children seem to have a specific problem ... with the representation of the movement of the internal argument to the subject position where it receives case and its thematic role" (Van der Lely 1996: 267-8).

As regards case, one can argue that, in 1996, Van der Lely was simply working within the syntactic theory generally available at that time. For this reason, she refers to case as being assigned, rather than being checked, as is proposed in later versions of Minimalist Syntax. However, the same cannot be said of her statement that the internal argument moves in order to receive a thematic role: Since the earliest proposals presented within the Principles and Parameters approach, it has been assumed that arguments receive their thematic roles in the sentence positions in which they are initially generated, specifically before any movement operations are performed (cf., e.g., Haegeman 1994: 310; O'Grady 1997: 289). Thus, the claim that arguments cannot receive certain thematic roles because they do not undergo movement, does not concur with assumptions about theta-role assignment in Minimalist Syntax (nor with such assumptions in previous theories within the Principles and Parameters approach).

On more than one occasion, Van der Lely states that her account offers an explanation for the problems children with SLI demonstrate with the interpretation of passive constructions (cf., e.g., Van der Lely 1996: 267; 2003: 127). This only holds true, however, if one accepts a key assumption which is contrary to that of the syntactic framework in which she claims to work, namely that internal arguments receive their thematic roles via movement. If not, it is not clear whether her account can in fact explain the problems these children demonstrate with 
the interpretation of passive constructions. However, the Computational Complexity Hypothesis does seem to provide an account of the problems that children with SLI have with the production of passive constructions, as this would involve movement - which, on the Computational Complexity Hypothesis, is commonly accepted to be a problematic operation for children with SLI.

\section{Possible alternative accounts}

As pointed out in section 1, children with SLI appear to have a preference for interpreting agentless passives as adjectival constructions (cf. Van der Lely 1996). For example, an utterance such as The dog is chased is usually assigned an interpretation on which is chased describes a property of the dog (i.e., the chased $d o g$ ), rather than one on which the dog is the theme undergoing some action by an unspecified agent (i.e., the dog is chased by someone). There are various possible explanations for this preference.

One explanation would be that the child does not differentiate between a copula and a passive auxiliary verb, a distinction that would be expressed by means of grammatical features within Minimal Syntax. Another possibility would be that children with SLI do not differentiate between active and passive sentences; hence, the dog is chased is simply interpreted as an active sentence. Support for this possibility may come from the fact that such children also have difficulty with the interpretation of "full" passives, that is, passive constructions containing an agent phrase, such as The dog is chased by the boy. Children with SLI usually interpret such sentences as if they are in the active voice: "the dog is the one who is chasing the boy" (Van der Lely 1996: 260-261). Again, a possible explanation could be that the child does not differentiate between, say, the past participial form and the passive form of the main verb, a distinction which is presumably expressed by means of grammatical features. This could especially be the case for child speakers of languages - such as Afrikaans and English in which the phonological forms of past and passive participles are generally indistinguishable.

A third possible explanation - one that holds for both agentless and full passives - concerns the assignment of the appropriate theta-roles to the nominal expressions functioning as arguments in a structure. Arguably, children with SLI overgeneralise the so-called Uniformity 
of Theta-Assignment Hypothesis (UTAH), proposed by Baker (1988). This hypothesis holds that identical thematic relationships between items correspond to identical structural relationships between such items at an underlying level of representation (Baker 1988: 46). In other words, an item bearing a particular theta-role is (always) associated with a particular, fixed, structural position. For example, in active constructions, the Agent role is associated with the structural subject position, i.e., the specifier of light verb $v$ (Radford 1997: 204). Hence, the child simply takes any argument occurring in the canonical structural subject position as the one receiving the Agent theta-role, irrespective of whether the structure in question is an active or a passive one. It could well be that this overgeneralisation of the UTAH is related to the second possibility mentioned above: The child fails to distinguish between the active form of the verb (which has the property of assigning an Agent theta-role) and the passive form (which lacks this property). Again, this failure could be ascribed to some or other problem involving the features associated with the verb forms in question.

\section{Conclusion}

Children with SLI (English-speaking ones as well as those speaking other languages) demonstrate problems with the interpretation and production of passive constructions. According to Van der Lely's (1994) account of SLI, the language deficits of these children stem from a selective impairment in establishing structural relationships between dependent constituents. This impairment leads to certain obligatory movement operations being optional in the grammar of these children. In this paper, it was argued that this account is not fully satisfactory. Three possible alternative explanations, all grounded in the framework of Minimalist Syntax, were proposed. The merit of these explanations needs to be determined by examining data on the actual interpretation and production of passive constructions by children with SLI from various languages. Experimental tasks examining such interpretation and production should preferably be complemented by tasks examining grammatical morphology related to tense and finiteness (as is the case in Rice, Wexler and Francois 2001). By doing so, it might be possible to establish links between the problems that children with SLI have with producing and interpreting passives, on the one hand, and the well-documented problems that they demonstrate with tense and other time-related grammatical morphology, on the other. 


\section{* Acknowledgement}

This material is based on work financially supported by The National Research Foundation (NRF). Any opinion, findings, conclusions or recommendations expressed in this material are those of the authors and therefore the NRF does not accept any liability in regard thereto.

\section{Notes}

1. Cf. also Marshall, Marinis and Van der Lely (2007).

2. Previously known as the "Representational Deficit for Dependent Relations Hypothesis" (RDDR).

3. An average of 3.7 passives per hour was recorded.

4. For example, The boy/the girl was seen by the girl/the boy vs. a non-reversible passive like The cheese/*the boy was eaten by the boy/*the cheese.

5. Cf., e.g., Chomsky (1995a: 1; 2002: 108) and Cheng and Sybesma (1995).

6. In more recent studies, Move is defined as "internal Merge", i.e., as a combination of Copy and Merge. Cf., e.g., Adger (2003: section 4.2); Chomsky (2006); Hornstein (2001: 18-19); Lasnik and Uriagereka (2005: section 5.7). The term "Move" is used here and below for the sake of simplicity.

7. C.f., e.g., Chomsky 1995b: 394. It is assumed in more recent versions of Minimalist Syntax that transfer from the narrow syntactic part of the computational system to the phonological and semantic components does not take place at one single point but rather at particular stages - technically known as "phases" - generally assumed to be $v \mathrm{P}$ and CP (cf., e.g., Hornstein et al. 2005: 347-8; Lasnik and Uriagereka 2005: 239). In short, "singular" Spell-Out has been replaced by multiple Spell-Out (cf. Chomsky 2006: 16).

8. The term "feature checking" will be used in a general, "theory-neutral" way; we leave open the possibility that what is here called "checking" could alternatively be defined as "assignment", "agreement" or "valuation" of features. Cf. Adger 2003: 167-169.

9. As stated in note 3, Move has since come to be seen not as a single operation, but as "a composite operation made up of two or more primitive processes, Copy and Merge" (Hornstein et al. 2005: 337). In Minimalist terms then, "Merge" is preferred over "Move", as the latter is a component of the former (Hornstein et al. 2005: 337).

\section{References}

Adger, D. 2003. Core syntax. A minimalist approach. New York: Oxford University Press. 
Allen, S. and M.B. Crago. 1993. Early acquisition of passive morphology in Inuktitut. In E. Clark (ed.) Proceedings of the $24^{\text {th }}$ Stanford Child Language Research Forum. Stanford: Centre for the Study of Language and Information. pp. 112-123.

Babyonyshev, M., L. Hart, and E. Grigorenko. 2005. The acquisition of passive constructions in Russian children with SLI. Paper presented at the $14^{\text {th }}$ annual meeting of Formal Approaches to Slavic Linguistics - The Princeton Meeting, 7 May 2005, Princeton University.

Baker, M.C. 1988. Incorporation: A theory of grammatical function changing. Chicago: University of Chicago Press.

Cheng, L. and R. Sybesma. 1995. Language is the perfect solution! Interview with Noam Chomsky. Glot International 1(9/10): 1, 31-34.

Chomsky, N. 1993. A minimalist program for linguistic theory. In K. Hale and S. Keyser (eds). The view from Building 20: Essays in linguistics in honor of Sylvian Bromberger. Cambridge: MIT Press. pp 1-52.

Chomsky, N. 1995a. The minimalist program. Cambridge, USA: MIT Press.

Chomsky, N. 1995b. Bare phrase structure. In G. Webelhuth (ed.) Government and binding theory and the minimalist program. Oxford: Blackwell Publishers. pp. 383-439.

Chomsky, N. 2002. On nature and language. Cambridge: Cambridge University Press.

Chomsky, N. 2006. Approaching UG from below. Unpublished manuscript, MIT.

Crago, M.B. and S.E.M. Allen. 1994. Morphemes gone askew: Linguistic impairment in Inuktitut. McGill Working Papers in Linguistics 10: 206-215.

Dalalakis, J. 1994. Developmental language impairment in Greek. McGill Working Papers in Linguistics 10: 216-227.

Fukuda, S.E. and S. Fukuda. 1994. Developmental language impairment in Japanese: A linguistic investigation. McGill Working Papers in Linguistics 10: 150-177.

Haegeman, L. 1994. Introduction to government and binding theory. Second edition. Cambridge, USA and Oxford: Blackwell.

Hornstein, N. 2001. Move! A minimalist theory of construal. Malden and Oxford: Blackwell Publishers.

Hornstein, N., J. Nunes, and K.K. Grohmann. 2005. Understanding minimalism. Cambridge: Cambridge University Press.

Lasnik, H. and J. Uriagereka. 2005. A course in minimalist syntax. Foundations and prospects. Malden, etc.: Blackwell Publishing. 
Leonard, L.B. 1998. Children with specific language impairment. Cambridge, USA and London: MIT Press.

Marshall, C., T. Marinis, and H. Van der Lely. 2007. Passive verb morphology: The effect of phonotactics on passive comprehension in typically developing and Grammatical-SLI children. Lingua 117: 1434-1447.

O'Grady, W. 1997. Semantics: The analysis of meaning. In W. O'Grady, M. Dobrovolsky and F. Katamba (eds). Contemporary linguistics: An introduction. London and New York: Longman. pp. 269-312.

Radford, A. 1997. Syntax. A minimalist introduction. Cambridge: Cambridge University Press.

Rice, M.L., K. Wexler, and J. Francois. 2001. SLI children's delayed acquisition of passive. Paper presented at the Boston University Conference on Language Development, 1-4 November 2001, Boston University.

Southwood, F. 2007. Specific language impairment in Afrikaans. Providing a Minimalist account for problems with grammatical features and word order. Utrecht: LOT.

Stark, R.E. and P. Tallal. 1981. Selection of children with specific language deficits. Journal of Speech and Hearing Disorders 46: 114-122.

Van der Lely, H.K.J. 1994. Canonical linking rules: Forward versus reverse linking in normally developing and specifically language-impaired children. Cognition 51: 29-72.

Van der Lely, H.K.J. 1996. Specifically language impaired children and normally developing children: Verbal passive vs. adjectival passive sentence interpretation. Lingua 98: 243272.

Van der Lely, H.K.J. 2003. Do hetereogeneous deficits require heterogeneous theories? SLI subgroups and the RDDR hypothesis. In Y. Levy and J. Schaeffer (eds). Language competence across populations. Toward a definition of specific language impairment. Mahwah: Lawrence Erlbaum Associates. pp. 111-133.

Van der Lely, H.K.J. 2005. Grammatical specific language impairment (G-SLI): Identifying and characterising the G-SLI group. Fréquence 17(3): 13-20.

Zwart, C.J-W. 1993. Dutch syntax. A minimalist approach. Doctoral dissertation, Rijksuniversiteit Groningen. 